\title{
Mixed meningitis: association of Acinetobacter calcoaceticus var lwoffi and Streptococcus faecium
}

\author{
PSA Sarma, S Mohanty
}

\begin{abstract}
Summary
We describe mixed bacterial meningitis in a young man due to Acinetobacter calcoaceticus var lwoffi and Streptococcus faecium. The combination of $\boldsymbol{A}$ calcoaceticus var lwoffi and $S$ faecium as aetiology of mixed bacterial meningitis has not been previously reported. The patient recovered completely without neurologic sequelae on chloramphenicol and penicillin.
\end{abstract}

Keywords: bacterial meningitis, Acinetobacter calcoaceticus, Streptococcus faecium

Mixed bacterial meningeal infection with simultaneous recovery of two or more bacterial species from an initial cerebrospinal fluid (CSF) sample ${ }^{1}$ is unusual and accounts for less than $1 \%$ of cases. ${ }^{2}$ The majority of cases occur in adults with a wide spectrum of aetiologic agents and predisposing factors (see box)..$^{1-4}$ The present report describes the successful management of a hitherto unreported case of a man with mixed meningitis due to $A$ calcoaceticus var lwoffi and $S$ faecium.

\section{Case report}

A previously healthy, 29-year-old man was admitted as an emergency, with a three-day history of fever, frontal headache, photophobia, vomiting, and drowsiness of one day's duration. He received intravenous ciprofloxacin and gentamicin for two days from a private medical practitioner prior to hospitalisation. On examination, he was found to be drowsy and febrile $\left(38.5^{\circ} \mathrm{C}\right)$. Signs of meningeal irritation were present and plantar reflexes were bilateral extensor. Ocular fundi examination revealed superficial haemorrhages in the right retina. There was no cranial nerve palsy or motor deficits. His haemoglobin was $15.5 \mathrm{~g} / \mathrm{dl}$ and white cell count $10.5 \times 10^{9} / 1$ (neutrophils $78 \%$ ). The hepatic and renal func-

\section{Department}

Microbiology

S Mohanty

Correspondence to Dr PSA Sarma, Senior Consultant (Medicine), MIG-II-437, Amdinagar, HUDCO, Bhilainagar, Madhya Pradesh- 490 006, India

Accepted 16 November 1994 tion tests were normal. A sickling test was negative and peripheral blood smear for malarial parasite was negative. Urinalysis, skull and chest $\mathrm{X}$-rays, non-contrast computer tomography (CT) scan of the head were normal. Ear, nose, and throat specialist's consultation was non-contributory. Lumbar puncture yielded turbid CSF under raised tension with white cells of $8 \times 10^{9} / 1$ (neutrophils $60 \%$ and mononuclears $40 \%$ ) and red cells of $4 \times 10^{9} / 1$. The concentration of CSF glucose was $1.72 \mathrm{mmol} / 1$ (serum glucose $6 \mathrm{mmol} / \mathrm{l}$ ) and that of protein was $238 \mathrm{mg} / \mathrm{dl}$. Gram's stain of CSF sediment showed Gram-positive cocci in pairs and short chains and a few Gram-negative coccobacilli. He received intravenous mannitol, chloramphenicol and crystalline penicillin. Two days later the CSF grew Gramnegative bacilli and Gram-positive cocci, subsequently identified as $A$ calcoaceticus var lwoffi and $S$ faecium, respectively. Antibiotic sensitivity of the bacterial isolates demonstrated $A$ calcoaceticus var lwoffi to be sensitive to chloramphenicol, penicillin and netilmicin and $S$ faecium only to chloramphenicol. Intravenous crystalline penicillin was given 20 lac units every 3 hours and chloramphenicol $1 \mathrm{~g}$ 6 hourly. The patient's blood and urine cultures grew no bacteria and ELISA test for HIV was negative. Over the next seven days, the neurologic condition progressively improved and fever abated. Repeat lumbar puncture on day 7 yielded a clear and normal CSF. Antibiotics were discontinued on day 10 and he was discharged on day 12 . The patient is well two months after discharge.

\section{Discussion}

Serious infections with Acinetobacter var lwoffi (box), including meningitis, are produced under conditions of decreased host resistance, or in the presence of instrumentation, or with prior broad spectrum antimicrobial therapy. ${ }^{5,6}$ Many of the bacteraemias due to acinetobacter are polymicrobial. ${ }^{6}$ Antibiotic sensitivities of acinetobacter strains vary and therapy has to be individualised, guided by the laboratory reports.

$S$ faecium is often found in polymicrobial infections and isolated from mixed bacterial infections arising from bowel flora. $S$ faecium is resistant to many antibiotics; meningitis due to $S$ faecium is not common. ${ }^{7}$

Mixed bacterial meningitis of the central nervous system in immunocompromised and 


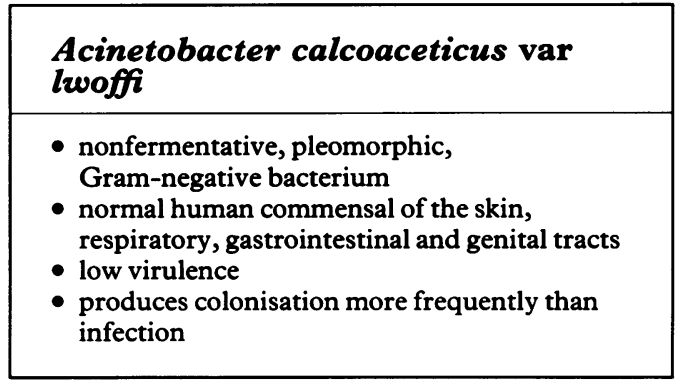

\begin{tabular}{|l|}
\hline Streptococcus faecium \\
\hline - significant human pathogen \\
- group D beta-haemolytic streptococci \\
(enterococci) \\
- commonly inhabits the skin, upper respiratory \\
tract, gastrointestinal tract or genitourinary \\
tract \\
- produces infections predominantly in the \\
elderly or debilitated, especially after \\
antibiotic treatment \\
\hline
\end{tabular}

immunologically competent patients has been reported both before and during the AIDS era. ${ }^{2,4}$ Both a review of acute bacterial meningitis among paediatric patients which included mixed bacterial isolates in 20 or 534 cases $^{1}$ and a review of 493 episodes of acute bacterial meningitis in 445 adults over a 27 -year period ${ }^{8}$ failed to mention $A$ calcoaceticus lwoffi and $S$ faecium as aetiologic agents of mixed meningitis.

1 Herweg JC, Middlekamp JN, Hartmann AF. Simultaneous mixed bacterial meningitis in children. $\mathcal{F}$ Pediatrics $1963 ; 63$ $76-83$.

2 Scheld WN. Bacterial meningitis and brain abscess. In: Isselbacher KJ, Braunwald S, Wilson JD, Martin JD, Fauci AS, Kasper DL, eds. Harrison's Principles of Internal Medicine. New York: McGraw-Hill Inc, 1994; pp 2296-309.

3 Frank GR, Rubin LG. Mixed meningitis with Bacteroides ovatus caused by an occult congenital dermal sinus. Pediat Infect Dis f 1988; 8: 401-3.

4 Sperber AD, Alkan N, Stemmer S, Avnon L, Schlaffer F. Polymicrobial central nervous system infection in the acquired immunodeficiency syndrome. $\mathcal{F}$ Neurol Neurosurg Psychiatry 1988; 51: 998-9.

\section{Learning points}

- bacterial meningitis due to more than one bacterium is rare

- broad-spectrum antibiotic usage may be a predisposing factor

Our patient received broad-spectrum antibiotics (ciprofloxacin and gentamicin) for two days prior to hospitalisation. We believe that broad-spectrum antibiotic usage was the predisposing factor in our patient who was otherwise healthy, causing immunocompromisation contributing to the development of mixed meningitis due to $A$ calcoaceticus and $S$ faecium.

The importance of diagnosing mixed infection is obvious since knowledge of aetiology greatly assists therapy. ${ }^{1}$ The overall therapeutic results reflect the age and immunologic status of the patient, the possible added severity of infection caused by two or more species of micro-organisms, and prompt institution of therapy guided by microbiology laboratory reports. The number of adult patients with mixed bacterial meningitis is clearly underestimated as an unknown proportion of patients escapes detection because appropriate cultures and immediate Gram's stain of the CSF are not done or the patients have already been given antibiotics. It is hoped that with the heightened awareness, more cases of mixed meningitis caused by multiple bacteria will be reported in the future.

5 Kobayashi TK, Yamaki T, Yoshino B et al. Meningitis with Acinetobacter calcoaceticus in cerebrospinal fluid. A case report. Acta Cytol 1983; 27: 281-4.

6 Berk SL, McCabe WR. Meningitis caused by Acinetobacter calcoaceticus var. antitratus. A specific hazard in neurosurgical patients. Arch Neurol 1981; 38: 95-8.

7 Murray BE. The life and times of enterococcus. Clin Microbiol Rev 1990; 3: 46-65.

8 Durand ML, Calderwood SB, Weber DJ et al. Acute bacterial meningitis in adults a review of 493 episodes. $N$ Engl f Med 1993; 328: 21-8. 